\title{
Does the Time-Consistency Problem Explain the Behavior of Inflation in the United States?
}

\author{
Peter N. Ireland* \\ Boston College
}

October 1998

\begin{abstract}
This paper derives the restrictions imposed by Barro and Gordon's theory of time-consistent monetary policy on a bivariate time-series model for inflation and unemployment and tests those restrictions using quarterly US data from 1960 through 1997. The results show that the data are consistent with the theory's implications for the long-run behavior of the two variables, indicating that the theory can explain inflation's initial rise and subsequent fall over the past four decades. The results also suggest that the theory must be extended to account more fully for the short-run dynamics that appear in the data.
\end{abstract}

$J E L:$ E31, E52, E61.

\section{Introduction}

Figure 1 shows the behavior of the inflation rate in the United States, as measured by quarter-to-quarter percentage changes in the GDP implicit price deflator. The graph serves to identify two major episodes in postwar US monetary

*Please address correspondence to: Peter N. Ireland, Boston College, Department of Economics, Carney Hall, 140 Commonwealth Avenue, Chestnut Hill, MA 02467-3806. Tel: (617) 552-3687. E-mail: peter.ireland@bc.edu. I would like to thank Marianne Baxter, Jon Faust, Michael Kiley, Robert King, Robert Rich, and conference participants at the Studienzentrum Gerzensee for many helpful comments and suggestions. 
history: the first, a period of rising inflation that extends from the early 1960s through the early 1980s, and the second, a period of falling inflation that begins in the early 1980s and continues to the present day. These two long-run trends appear more clearly in the 10-year centered moving average that is also displayed in figure $1 .{ }^{1}$ Why did US policymakers allow inflation to drift higher throughout the 1960s, 1970s, and early 1980s? And, conversely, what factors have contributed to their ability to bring inflation down more recently?

Barro and Gordon's (1983) celebrated model of time-consistent monetary policy offers answers to these questions. In Barro and Gordon's model, a policymaker desires to reduce unemployment and, lacking the ability to commit in advance to a monetary policy rule, is tempted to do so in each period by creating surprise inflation in an effort to exploit an expectational Phillips curve. Private agents in the model have rational expectations, however; they recognize that the government faces this temptation to inflate and adjust their decisions accordingly. In equilibrium, therefore, unemployment is no lower than it would otherwise be, and yet the rate of inflation is inefficiently high. Moreover, given the convex costs assigned to unemployment in the model, the policymaker's temptation to inflate - and hence the magnitude of the inflationary bias itself - becomes increasingly significant as the natural rate of unemployment rises. Interpreting their model as a positive theory of monetary policy, Barro and Gordon argue that an upward trend in the natural rate of unemployment during the 1960s and 1970s allows their theory to account for the coincident upward trend in inflation.

In fact, estimates of the time-varying natural rate of unemployment constructed, for example, by Gordon (1997) and Staiger, Stock, and Watson (1997) typically indicate not only that the natural rate followed an upward trend during the 1960s, 1970s, and early 1980s but also that the natural rate has reversed course and fallen since then. Indeed, figure 2 shows that trends appear in the actual civilian unemployment rate that parallel those found in inflation.

Figures 1 and 2, therefore, suggest that Barro and Gordon's model can potentially explain inflation's initial rise and subsequent fall over the past four decades. They call out for a more detailed analysis that uses the Barro-Gordon model as a basis for statistical tests of the hypothesis that the time-consistency problem underlies the behavior of inflation in the United States. This paper performs such an analysis. ${ }^{2}$ Accordingly, the following sections outline a version

\footnotetext{
${ }^{1}$ King and Watson (1994) find that a similar picture emerges when the data are passed through a filter that is optimally designed to isolate long-run trends.

${ }^{2}$ Parkin (1993) also suggests that the time-consistency problem can explain the behavior of
} 
of Barro and Gordon's model of time-consistent monetary policy, derive the restrictions that the theory imposes on a bivariate time-series model for inflation and unemployment, and test those restrictions using quarterly US data from 1960 through 1997.

\section{The Barro-Gordon Model and Its Implications}

This section modifies Barro and Gordon's (1983) model by allowing the natural rate of unemployment to follow a more general autoregressive process that contains a unit root and by introducing control errors for inflation. The first extension permits the model to account for the fact, documented below, that the actual unemployment rate in the United States is nonstationary. The second extension permits the model to account for transitory deviations between the actual unemployment rate and the natural rate, which do not arise under Barro and Gordon's original specification.

The actual unemployment rate $U_{t}$ fluctuates around the natural rate $U_{t}^{n}$ in response to deviations of the actual inflation rate $\pi_{t}$ from the expected rate $\pi_{t}^{e}$ according the expectational Phillips curve

$$
U_{t}=U_{t}^{n}-\alpha\left(\pi_{t}-\pi_{t}^{e}\right)
$$

where $\alpha>0$. The natural rate, in turn, fluctuates over time in response to a real shock $\varepsilon_{t}$ according to the autoregressive process

$$
U_{t}^{n}-U_{t-1}^{n}=\lambda\left(U_{t-1}^{n}-U_{t-2}^{n}\right)+\varepsilon_{t}
$$

where $1>\lambda>-1$ and $\varepsilon_{t}$ is serially uncorrelated and normally distributed with mean zero and standard deviation $\sigma_{\varepsilon}$.

The monetary authority cannot commit to a policy rule. Instead, at the beginning of each period $t=0,1,2, \ldots$, after private agents have formed their expectation $\pi_{t}^{e}$ but before the realization of the real shock $\varepsilon_{t}$, the policymaker chooses a planned rate of inflation $\pi_{t}^{p}$. Actual inflation for the period is then determined as the sum of $\pi_{t}^{p}$ and a control error $\eta_{t}$, so that

$$
\pi_{t}=\pi_{t}^{p}+\eta_{t}
$$

inflation in the United States, but does not test this hypothesis. Baxter (1988) emphasizes the need for statistical tests that establish the empirical relevance of the time-consistency problem, but stops short of actually performing such tests. 
where $\eta_{t}$ is serially uncorrelated and normally distributed with mean zero, standard deviation $\sigma_{\eta}$, and covariance $\sigma_{\varepsilon \eta}$ with $\varepsilon_{t}$.

The policymaker selects $\pi_{t}^{p}$ in an effort to minimize a loss function that penalizes variations of unemployment and inflation around target values $k U_{t}^{n}$ and zero:

$$
(1 / 2)\left(U_{t}-k U_{t}^{n}\right)^{2}+(b / 2) \pi_{t}^{2},
$$

with $1>k>0$ and $b>0$ so that, in particular, the policymaker wishes to push the actual unemployment rate below the natural rate. Using (1) and (3), the policymaker's problem becomes

$$
\min _{\pi_{t}^{p}} E_{t-1}\left\{(1 / 2)\left[(1-k) U_{t}^{n}-\alpha\left(\pi_{t}^{p}+\eta_{t}-\pi_{t}^{e}\right)\right]^{2}+(b / 2)\left(\pi_{t}^{p}+\eta_{t}\right)^{2}\right\},
$$

where $E_{t-1}$ denotes the expectation at the beginning of period $t$ or, equivalently, at the end of period $t-1$. The first-order condition for this problem is

$$
\alpha E_{t-1}\left[(1-k) U_{t}^{n}-\alpha\left(\pi_{t}^{p}+\eta_{t}-\pi_{t}^{e}\right)\right]=b E_{t-1}\left(\pi_{t}^{p}+\eta_{t}\right) .
$$

Private agents know the structure of the economy and understand the policymaker's time-consistency problem. In equilibrium, therefore, they correctly anticipate the policymaker's actions, so that $\pi_{t}^{e}=\pi_{t}^{p}$. Using this equilibrium condition, along with the fact that $E_{t-1} \eta_{t}=0$, (4) simplifies to

$$
\pi_{t}^{p}=\pi_{t}^{e}=\alpha A E_{t-1} U_{t}^{n},
$$

where

$$
A=(1-k) / b>0 .
$$

If the policymaker could commit to a policy rule at the beginning of time, he would choose a planned rate of inflation equal to zero in every period. Thus, (5) reveals that the inflationary bias resulting from the policymaker's inability to commit depends positively on the expected natural rate $E_{t-1} U_{t}^{n}$. Here, as in Barro and Gordon's original model, the equilibrium inflation rate moves together with the natural rate of unemployment.

Equations (1), (3), and (5) imply that

$$
U_{t}=U_{t}^{n}-\alpha \eta_{t},
$$

which shows how the control error for inflation allows the actual unemployment rate to fluctuate, in equilibrium, around the natural rate. Combining (6) with (2) yields

$$
U_{t}=U_{t-1}^{n}+\lambda \Delta U_{t-1}^{n}+\varepsilon_{t}-\alpha \eta_{t}
$$


where $\Delta U_{t-1}^{n}=U_{t-1}^{n}-U_{t-2}^{n}$ denotes the change in the natural rate during period $t-1$. Equations (2), (3), and (5), meanwhile, imply that

$$
\pi_{t}=\alpha A U_{t-1}^{n}+\alpha A \lambda \Delta U_{t-1}^{n}+\eta_{t} .
$$

Separately, (7) and (8) indicate that both inflation and unemployment are nonstationary, inheriting unit roots from the underlying process for the natural rate. Together, however, they imply that

$$
\pi_{t}-\alpha A U_{t}=-\alpha A \varepsilon_{t}+\left(1+\alpha^{2} A\right) \eta_{t}
$$

which shows that a linear combination of inflation and unemployment is stationary. Equation (9), therefore, summarizes the constraint that Barro and Gordon's theory imposes on the long-run behavior of inflation and unemployment: according to the model, these variables should be nonstationary but cointegrated. A statistical test of this cointegration constraint will determine whether the BarroGordon model can successfully explain inflation's initial rise and subsequent fall over the past four decades.

Taking first differences of (6), solving for $\Delta U_{t}^{n}=U_{t}^{n}-U_{t-1}^{n}$, and substituting the result into (2) yields

$$
\Delta U_{t}=\lambda \Delta U_{t-1}+\varepsilon_{t}-\alpha \eta_{t}+\alpha(1+\lambda) \eta_{t-1}-\alpha \lambda \eta_{t-2},
$$

where $\Delta U_{t}=U_{t}-U_{t-1}$ denotes the change in the actual unemployment rate during period $t$. Together, (9) and (10) can be written in the form of a vector $\operatorname{ARMA}(1,2)$ for the stationary linear combination of inflation and unemployment and the stationary change in unemployment:

$$
\begin{aligned}
{\left[\begin{array}{l}
\pi_{t}-\alpha A U_{t} \\
\Delta U_{t}
\end{array}\right]=} & {\left[\begin{array}{ll}
0 & 0 \\
0 & \lambda
\end{array}\right]\left[\begin{array}{l}
\pi_{t-1}-\alpha A U_{t-1} \\
\Delta U_{t-1}
\end{array}\right] } \\
& +\left[\begin{array}{ll}
-\alpha A & 1+\alpha^{2} A \\
1 & -\alpha
\end{array}\right]\left[\begin{array}{l}
\varepsilon_{t} \\
\eta_{t}
\end{array}\right] \\
& +\left[\begin{array}{ll}
0 & 0 \\
0 & \alpha(1+\lambda)
\end{array}\right]\left[\begin{array}{l}
\varepsilon_{t-1} \\
\eta_{t-1}
\end{array}\right]+\left[\begin{array}{ll}
0 & 0 \\
0 & -\alpha \lambda
\end{array}\right]\left[\begin{array}{l}
\varepsilon_{t-2} \\
\eta_{t-2}
\end{array}\right] .
\end{aligned}
$$

The within-equation and cross-equation restrictions appearing in (11) summarize the constraints that Barro and Gordon's theory imposes on the short-run behavior of inflation and unemployment. A statistical test of these restrictions will determine how well the Barro-Gordon model explains the dynamic relationships between these two variables that can be found in the data. 


\section{Testing the Model's Implications}

This section tests the cointegration constraint shown in (9) to see whether the time-consistency problem can explain the long-run behavior of inflation and unemployment in the United States. In addition, it tests the restrictions shown in (11) to assess the model's ability to account for the short-run dynamics that appear in the data. Both sets of statistical tests use quarterly, seasonally-adjusted data that are drawn from the Federal Reserve Bank of St. Louis' FRED database. The inflation rate is measured, as in figure 1, using quarter-to-quarter changes in the GDP implicit price deflator; the unemployment rate is measured, as in figure 2, using the civilian unemployment rate. King and Watson (1997) find evidence of a significant break in the time-series behavior of inflation and unemployment occurring around 1970. Therefore, all tests are performed with data from both the full sample period, 1960:1-1997:2, and the subsample beginning in 1970:1.

\subsection{Testing the Long-Run Restriction}

Equations (7) and (8) show that according to the model, both the inflation rate and the unemployment rate ought to be nonstationary. Thus, table 1 reports results from the Phillips-Perron (1988) test described by Hamilton (1994, Ch.17), applied to check for unit roots in the two series. The table shows estimates of $\rho$, the slope coefficient from a regression of each variable on a constant and its own lagged value, as well as $\tau$, the conventional $t$-statistic for testing the hypothesis that $\rho=1$. The Phillips-Perron statistic, denoted $Z_{\tau}$, adjusts the conventional $t$-statistic to allow for serial correlation in the regression error. This adjustment uses Newey and West's (1987) method to estimate the variance of the regression error; Andrews' (1991) method is used to select a value for the lag truncation parameter $q$ required to form the Newey-West estimator, assuming that the process for the regression error is well-approximated by a first-order autoregression.

The results show that the null hypothesis that the process for unemployment contains a unit root cannot be rejected in either sample period. The results for inflation are a little less clear. In the full sample, the unit root hypothesis for inflation can be rejected, but only at the 0.10 significance level; in the post-1970 sample, the unit root hypothesis cannot be rejected. Based on these results, along with the others presented below, it seems appropriate to regard both inflation and unemployment as nonstationary. 
Table 2 reports results from the Phillips-Ouliaris (1990) test described by Hamilton (1994, Ch.19), applied to check for the cointegrating relationship between inflation and unemployment implied by (9). The table shows estimates of $\gamma$, the coefficient from a regression of $\pi_{t}$ on $U_{t}$, along with the statistics needed to test for a unit root in the residual from this regression. For both sample periods, the hypothesis that inflation and unemployment are not cointegrated can be rejected at the 0.05 significance level. ${ }^{3}$

One potential drawback of the residual-based, Phillips-Ouliaris test, also discussed by Hamilton (1994, pp.589-590), concerns the fact that the results may hinge sensitively on which variable, inflation or unemployment, appears as the dependent variable in the initial regression. Here, however, (9) indicates that the hypothesized cointegrating relationship is of the form $\pi_{t}-\gamma U_{t}$, making inflation the obvious choice of dependent variable. Nevertheless, the robustness of the Phillips-Ouliaris test results is easily established using Johansen's (1988) maximum likelihood approach, described by Hamilton (1994, Ch.20), which does not require a choice of normalization.

Thus, table 2 also reports statistics associated with the Johansen test for cointegration: the two eigenvalues $\lambda_{1}$ and $\lambda_{2}$ used in evaluating Johansen's likelihood function, the estimates of the cointegrating vector for $\pi_{t}$ and $U_{t}$, and the likelihood ratio statistic $L R=-T \ln \left(1-\lambda_{1}\right)$ used to test the null hypothesis of no cointegration. The results of the Johansen tests confirm those of the PhillipsOuliaris tests, rejecting the null hypothesis of no cointegration between inflation and unemployment at the 0.01 significance level for the full sample and at the 0.05 significance level for the post-1970 sample.

Thus, the results in table 2 strongly support the Barro-Gordon model's implications for the long-run behavior of inflation and unemployment; as predicted by (9), the two variables are cointegrated. These results are, in particular, consistent with the view that inflation's initial rise and subsequent fall over the past four decades can be explained by the Federal Reserve's inability to commit to a monetary policy that reduces its temptation to exploit the Phillips curve. When coupled with the upward trend in unemployment during the 1960s, 1970s, and early 1980s, this inability to commit yields a coincident rise in inflation; when coupled with the downward trend in unemployment since the early 1980s, this inability to commit yields a coincident fall in inflation.

\footnotetext{
${ }^{3}$ The strong evidence that unemployment is nonstationary, together with the strong evidence that inflation and unemployment are cointegrated, supports the hypothesis, accepted above, that inflation is nonstationary.
} 


\subsection{Testing the Short-Run Restrictions}

Focusing now on the theory's implications for the short-run behavior of inflation and unemployment, table 3 presents maximum likelihood estimates of the model's parameters, obtained by mapping (11), the constrained $\operatorname{AMRA}(1,2)$ for $\pi_{t}-\alpha A U_{t}$ and $\Delta U_{t}$, into state-space form and using the Kalman filter to evaluate the likelihood function, as suggested by Hamilton (1994, Ch.13). The parameter estimates are stable across the two sample periods. Moreover, the standard errors, computed by taking the square roots of the diagonal elements of the inverted matrix of the maximized log likelihood function's second derivatives, are small, implying that each parameter is estimated with a fair degree of accuracy.

The estimates of $\alpha$ suggest that the Phillips curve is quite steep, with each percentage-point of surprise inflation generating a fall in the unemployment rate of only 0.15 percentage points. Although the parameters $k$ and $b$ are not individually identified, the estimates of $A=(1-k) / b$ exceed unity; the restriction $1>k>0$ then implies that $b$ must be less than one. Evidently, the Federal Reserve placed more weight on its goals for unemployment than on its goals for inflation over both sample periods. ${ }^{4}$ The estimates of $\lambda$ are positive, as expected. Finally, the positive estimates of the covariance $\sigma_{\varepsilon \eta}$ indicate that unfavorable shocks to the natural rate tend to coincide with unfavorable shocks to inflation; these estimates support the idea that $\varepsilon_{t}$ represents a real, or supplyside, disturbance.

The within-equation and cross-equation restrictions that appear in (11) may be tested by comparing the fit of the constrained $\operatorname{ARMA}(1,2)$ to the fit of an unconstrained $\operatorname{ARMA}(1,2)$ of the same form. The constrained model has 6 parameters, while an unconstrained $\operatorname{ARMA}(1,2)$ for a stationary linear combination of inflation and unemployment of the form $\pi_{t}-\gamma U_{t}$ and the stationary change in unemployment $\Delta U_{t}$ has 16 parameters. ${ }^{5}$ Thus, the theory places 10 restrictions on a bivariate time-series model for these stationary variables: if $L^{c}$ denotes the maximized value of the log likelihood function for the constrained model, and if $L^{u}$ denotes the maximized value of the log likelihood function for the unconstrained model, then the likelihood ratio statistic $L R=2\left(L^{u}-L^{c}\right)$ has a chi-square distribution with 10 degrees of freedom under the null hypothesis

\footnotetext{
${ }^{4}$ This conclusion must be accepted with some caution, however: when confidence intervals are placed around the estimates of $A$, the implied values for $b$ are not necessarily less than one.

${ }^{5}$ The 16 parameters of the unconstrained model include $\gamma$, the parameter in the cointegrating relationship, the four autoregresive parameters, the eight moving-average parameters, and the three distinct parameters in the covariance matrix for the innovations.
} 
that the constraints hold.

Table 3 shows that $L R=274.8750$ for the full sample and $L R=196.0684$ for the post-1970 subsample. The 0.001 critical value for a chi-square random variable with 10 degrees of freedom is 29.6. Thus, the likelihood ratio tests overwhelmingly reject the model's short-run restrictions in (11).

What is the source of this massive rejection of the model's dynamic restrictions? According to (9) - which is also the first equation in (11) — the stationary linear combination of inflation and unemployment identified by the model ought to be serially uncorrelated. The values of $\rho$ reported in the top panel of table 2 , however, indicate that $\pi_{t}-\alpha A U_{t}$, while stationary, is also highly persistent. Clearly, Barro and Gordon's model must be extended to explain this persistence if it is to provide a more accurate characterization of the dynamic behavior of inflation and unemployment.

Given the large number of restrictions that appear in (11), however, it comes as no surprise that statistical tests reject the constrained model. After all, the underlying theory is described by three simple equations, listed above as (1)-(3); it would be unreasonable to expect this simple structure to account for all of the dynamics that can be found in the data. More impressive, therefore, is the fact that the time-series model (11) that is implied by this simple theory can be used to obtain reasonable, stable, and precise estimates of the parameters listed in table 3 .

\section{Conclusion}

Does the time-consistency problem explain the behavior of inflation in the United States? Barro and Gordon's (1983) model of time-consistent monetary policy implies that long-run trends in the natural rate of unemployment will introduce similar trends into the inflation rate when the central bank cannot commit to a monetary policy rule. The tests results presented above, which indicate that inflation and unemployment are cointegrated, are consistent with this implication. Thus, at a minimum, the results suggest that the answer to the question posed in this paper is "yes," that the time-consistency problem may underlie inflation's initial rise and subsequent fall over the past four decades.

Tests of the model's short-run restrictions, also presented above, indicate that the model is less successful at accounting for the dynamic, quarter-to-quarter comovement of inflation and unemployment in the United States. The version of Barro and Gordon's model used here, however, is extremely simple; consisting 
of just three linear equations, it makes no attempt, for instance, to explain the lagged but highly persistent effects on both real and nominal variables that are frequently associated with monetary policy in the US economy. As surveys by Blackburn and Christensen (1989) and Rogoff (1989) make clear, Barro and Gordon's model has already been extended in a variety of ways in order to produce additional insights into the optimal design of monetary policymaking procedures and institutions. Perhaps, similarly, the model can be extended to more accurately capture the short-run behavior of inflation and unemployment. 6

Looking forward, what implications do the results obtained here have for monetary policy in the United States? DeLong (1997) and Taylor (1997) argue that the behavior of inflation in the US economy is attributable not to the timeconsistency problem, but to the gradual process through which policymakers and academic economists learn about the economy. ${ }^{7}$ They suggest that during the 1960s and 1970s, as academic economists came to believe in an exploitable Phillips curve trade-off, policymakers were encouraged to accept a higher rate of inflation in exchange for a lower rate of unemployment; the failure of this experiment then paved the way for the rational expectations revolution and the more recent era of lower inflation. According to this view, the fundamental source of high inflation - economists' and policymakers' ignorance about the structure of the economy - has been removed; hence, the inflationary experiences of the 1960s and 1970s will not be repeated.

The theory and evidence presented here do not invite such optimism. According to the Barro-Gordon model, the inflation of the 1960s and 1970s has as its proximate cause a string of bad luck, in the form of a series of negative and persistent supply-side shocks that worked to increase the natural rate of unemployment. Similarly, from the viewpoint of this model, the disinflation of the 1980s and 1990s represents the product of good luck, in the form of a series of positive and persistent supply-side shocks that have worked to decrease the natural rate. According to this alternative view, therefore, nothing fundamental has changed. The Fed must receive a mandate that allows it to place less weight

\footnotetext{
${ }^{6}$ Broadbent and Barro (1997) make some progress in this direction by extending the original Barro-Gordon model to provide a more detailed description of the economy and of the exogenous shocks that hit the economy. But while Broadbent and Barro successfully estimate this extended model via maximum likelihood, they do not test its restrictions nor do they comment more generally on its ability to explain the behavior of inflation in the United States. Clearly, more work needs to be done along these lines.

${ }^{7}$ Sargent (1997) also explores this idea.
} 
on developments in the real economy and to commit more credibly to a lowinflation policy. Otherwise, sooner or later, bad luck - and high inflation - will return to haunt us.

\section{References}

Andrews, Donald W.K. "Heteroskedasticity and Autocorrelation Consistent Covariance Matrix Estimation." Econometrica 59 (May 1991): 817-858.

Barro, Robert J. and David B. Gordon. "A Positive Theory of Monetary Policy in a Natural Rate Model." Journal of Political Economy 91 (August 1983): 589-610.

Baxter, Marianne. "Toward an Empirical Assessment of Game-Theoretic Models of Policymaking: A Comment." Carnegie-Rochester Conference Series on Public Policy 28 (Spring 1988): 141-151.

Blackburn, Keith and Michael Christensen. "Monetary Policy and Policy Credibility: Theories and Evidence." Journal of Economic Literature 27 (March 1989): 1-45.

Broadbent, Ben and Robert J. Barro. "Central Bank Preferences and Macroeconomic Equilibrium." Journal of Monetary Economics 39 (June 1997): $17-43$.

DeLong, J. Bradford. "America's Peacetime Inflation: The 1970s." In Christina D. Romer and David H. Romer, eds. Reducing Inflation: Motivation and Strategy. Chicago: University of Chicago Press, 1997.

Gordon, Robert J. "The Time-Varying NAIRU and its Implications for Economic Policy." Journal of Economic Perspectives 11 (Winter 1997): 11-32.

Hamilton, James D. Time Series Analysis. Princeton: Princeton University Press, 1994.

Johansen, Soren. "Statistical Analysis of Cointegration Vectors." Journal of Economic Dynamics and Control 12 (June/September 1988): 231-254.

King, Robert G. and Mark W. Watson. "The Post-War U.S. Phillips Curve: A Revisionist Econometric History." Carnegie-Rochester Conference Series on Public Policy 41 (December 1994): 157-219. 
Newey, Whitney K. and Kenneth D. West. "A Simple, Positive Semi-Definite, Heteroskedasticity and Autocorrelation Consistent Covariance Matrix." Econometrica 55 (May 1987): 703-708.

Parkin, Michael. "Inflation in North America." In Kumiharu Shigehara, ed. Price Stabilization in the 1990s: Domestic and International Policy Requirements. London: Macmillan Press, 1993.

Phillips, P.C.B. and S. Ouliaris. "Asymptotic Properties of Residual Based Tests for Cointegration." Econometrica 58 (January 1990): 165-193.

Phillips, Peter C.B. and Pierre Perron. "Testing for a Unit Root in Time Series Regression." Biometrika 75 (June 1988): 335-346.

Rogoff, Kenneth. "Reputation, Coordination, and Monetary Policy." In Robert J. Barro, ed. Modern Business Cycle Theory. Cambridge: Harvard University Press, 1989.

Sargent, Thomas J. "The Conquest of American Inflation." Manuscript. Stanford: Stanford University, Hoover Institution, November 1997.

Staiger, Douglas, James H. Stock, and Mark W. Watson. "How Precise Are Estimates of the Natural Rate of Unemployment?" In Christina D. Romer and David H. Romer, eds. Reducing Inflation: Motivation and Strategy . Chicago: University of Chicago Press, 1997.

Taylor, John B. "Comment." In Christina D. Romer and David H. Romer, eds. Reducing Inflation: Motivation and Strategy. Chicago: University of Chicago Press, 1997. 
Table 1. Unit Root Tests

1960:1-1997:2

$\begin{array}{ccccc} & \rho & \tau & q & Z_{\tau} \\ \text { Unemployment Rate } & 0.9743 & -1.3627 & 5 & -2.2161 \\ \text { Inflation Rate } & 0.8928 & -2.8739 & 0 & -2.8739^{*}\end{array}$

1970:1-1997:2

$\begin{array}{ccccc} & \rho & \tau & q & Z_{\tau} \\ \text { Unemployment Rate } & 0.9519 & -1.7880 & 4 & -2.5186 \\ \text { Inflation Rate } & 0.8788 & -2.5362 & 0 & -2.5362\end{array}$

Notes: The table shows estimates of $\rho$, the slope coefficient from a regression of each variable on a constant and its own lagged value, as well as $\tau$, the conventional $t$-statistic for testing the hypothesis that $\rho=1$. The Phillips-Perron (1988) statistic, $Z_{\tau}$, adjusts the conventional $t$-statistic to allow for serial correlation in the regression error. This adjustment uses Newey and West's (1987) method to estimate the variance of the regression error and Andrews' (1991) method to select a value for the lag truncation parameter $q$ required to form the Newey-West estimator, assuming that the process for the regression error is well-approximated by a first-order autoregression. Critical values for $Z_{\tau}$ are reported under the heading "case 2" in Hamilton's (1994, p.763) table B.6.

* denotes significance at the $10 \%$ level. 


\section{Table 2. Cointegration Tests}

\begin{tabular}{cccccc} 
Phillips-Ouliaris Test & \multicolumn{1}{c}{} \\
Sample Period & $\gamma$ & $\rho$ & $\tau$ & $q$ & $Z_{\tau}$ \\
1960:1-1997:2 & 0.1680 & 0.8865 & -2.9805 & 0 & $-2.9805^{* *}$ \\
1970:1-1997:2 & 0.1791 & 0.8709 & -2.7603 & 0 & $-2.7603^{* *}$
\end{tabular}

Johansen Test

Sample Period $\quad \lambda_{1} \quad \lambda_{2} \quad$ Cointegrating Vector $\quad L R=-T \ln \left(1-\lambda_{1}\right)$

1960:1-1997:2 $\quad 0.1010 \quad 0.0022 \quad 1.7059 \pi_{t}-0.3173 U_{t} \quad 15.7516^{* * *}$

$1970: 1-1997: 2 \quad 0.1189 \quad 0.0050 \quad 1.6985 \pi_{t}-0.3303 U_{t} \quad 13.6701^{* *}$

Notes: For the Phillips-Ouliaris (1990) test, the table shows estimates of $\gamma$, the coefficient from a regression of inflation on unemployment, as well as $\rho$, the coefficient from a regression of the residual from the inflationunemployment regression on its own lagged value, and $\tau$, the conventional $t$-statistic for testing the hypothesis that $\rho=1$. The statistics $q$ and $Z_{\tau}$ are computed as described in the notes to table 1 . Critical values for the test statistic $Z_{\tau}$ are reported under the heading "case 1" in Hamilton's (1994, p.766) table B.9. For the Johansen (1988) test, the table shows the two eigenvalues $\lambda_{1}$ and $\lambda_{2}$ used in evaluating Johansen's likelihood function, the estimated cointegrating vectors, and the likelihood ratio statistic $L R$ for testing the null hypothesis of no cointegration. Critical values for $L R$ are reported under the heading "case 1" in Hamilton's (1994, p.768) table B.11.

${ }^{* *}$ and ${ }^{* * *}$ denote significance at the $5 \%$ and $1 \%$ levels. 


\section{Table 3. Maximum Likelihood Estimates}

1960:1-1997:2

$\begin{array}{ccc} & \text { Estimate } & \text { Standard Error } \\ \alpha & 0.1474 & 0.0579 \\ A & 1.1550 & 0.4546 \\ \lambda & 0.5686 & 0.0682 \\ \sigma_{\varepsilon} & 0.2675 & 0.0159 \\ \sigma_{\eta} & 0.6299 & 0.0370 \\ \sigma_{\varepsilon \eta} & 0.0573 & 0.0148\end{array}$

$L^{c}=$ maximized value of constrained $\log$ likelihood $=-148.6597$

$L^{u}=$ maximized value of unconstrained $\log$ likelihood $=-11.2222$

$L R=2\left(L^{u}-L^{c}\right)=274.8750$

1970:1-1997:2

$\begin{array}{ccc} & \text { Estimate } & \text { Standard Error } \\ \alpha & 0.1537 & 0.0641 \\ A & 1.1744 & 0.4894 \\ \lambda & 0.5505 & 0.0810 \\ \sigma_{\varepsilon} & 0.2905 & 0.0202 \\ \sigma_{\eta} & 0.6530 & 0.0446 \\ \sigma_{\varepsilon \eta} & 0.0725 & 0.0200\end{array}$

$L^{c}=$ maximized value of constrained log likelihood $=-119.8246$

$L^{u}=$ maximized value of unconstrained $\log$ likelihood $=-21.7904$

$L R=2\left(L^{u}-L^{c}\right)=196.0684$ 


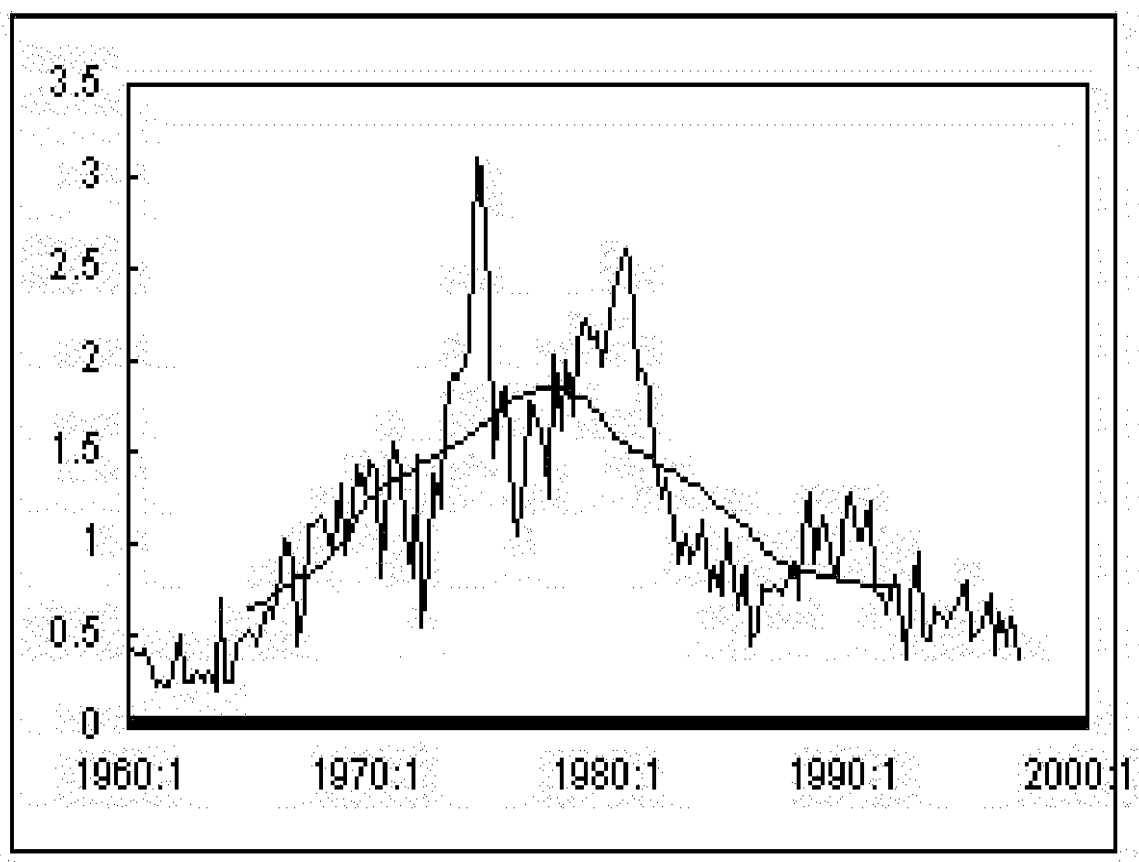

Figure 1. Quarterly Inflation Rate and 10-Year Centered Moving Average, United States 


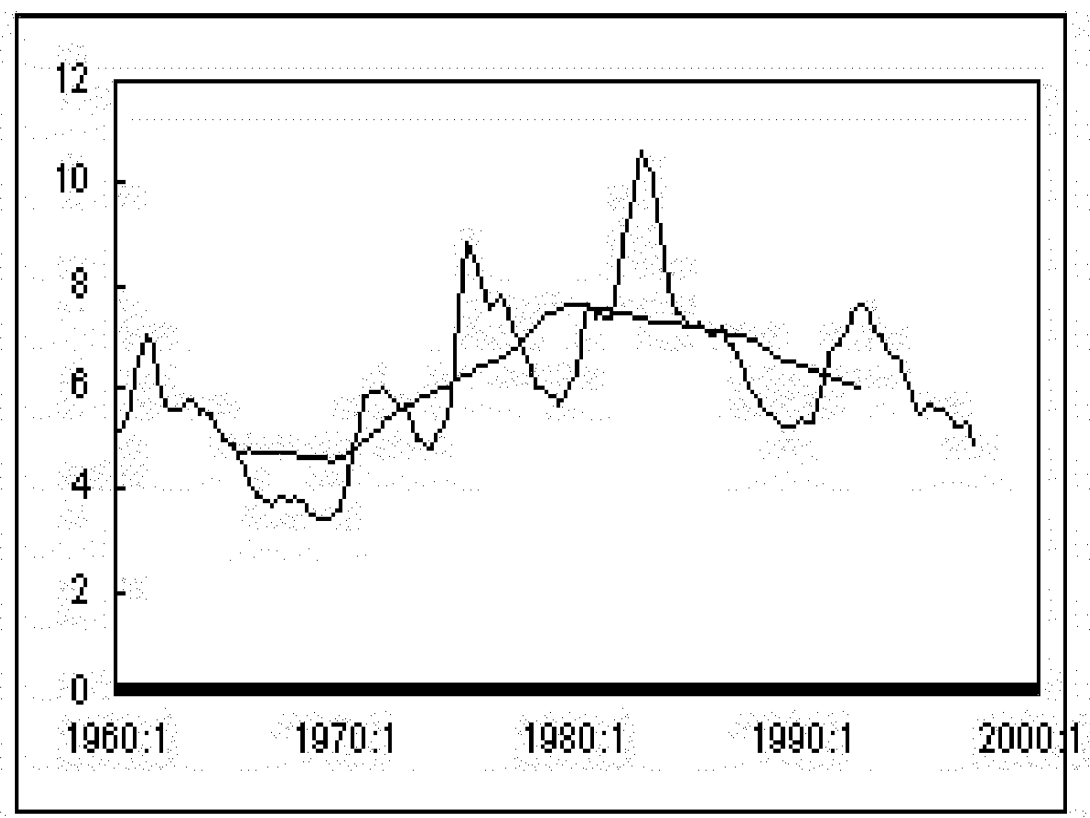

Figure 2. Unemployment Rate and 10-Year Centered Moving Average, United States 